\title{
A construção do sentido na linguagem: o lugar da enunciação e da argumentação linguística
}

The construction of meaning within language: the place of enunciation and linguistic argumentation

\author{
Lauro Gomes ${ }^{1}$ \\ Pontifícia Universidade Católica do Rio Grande do Sul, Escola de Humanidades, \\ Programa de Pós-Graduação em Letras. Porto Alegre, RS, Bras \\ Luiz Francisco Dias ${ }^{2}$ \\ Universidade Federal de Minas Gerais, Faculdade de Letras. Belo Horizonte, MG, Brasil \\ Leci Borges Barbisan ${ }^{3}$ \\ Pontifícia Universidade Católica do Rio Grande do Sul, Escola de Humanidades
}

' Doutorando em Linguística no Programa de PósGraduação em Letras da Escola de Humanidades da Pontifícia Universidade Católica do Rio Grand Conselho Nacional de Desenvolvimento Científico e Tecnológico (CNPq).

(1) https://orcid.org/0000-0002-1302-2693

Email: lauro.gomes.001@acad.pucrs.br

Professor Titular da Universidade Federal de Conselho Nacional de Desenvolvimento Cient́fico e Tecnológico (CNPq).

(Di) https://orcid. org/0000-0003-0819-4797

E-mail: luiz.francisco@uol.com.br

Professora Titular do Programa de Pós-Graduação em Letras da Escola de Humanidades da Pontificia Universidade Catolica do Rio Grande do Sul (PPGL/PUCRS) e pesquisadora bolsista do e Tecnológico (CNPq).

(i) https://orcid.org/0000-0002-9938-9540

E-mail: barbisan@pucrs.br
O discan campo da semântica, especificamente os estudos da enunciação e da argumentação, aborda fenômenos linguísticodiscursivos cujas origens remontam às reflexões de filósofos gregos sobre a linguagem, como as que, em forma de diálogo, são apresentadas no Crátilo, em O Sofista e em Teeteto de Platão, e também as que se encontram desenvolvidas na Retórica e na Poética de Aristóteles, apenas para citar alguns exemplos. A partir de textos como esses de filosofia clássica - que já buscavam explicar, entre outras questões, a relação entre os nomes e as coisas, a presença do Outro na constituição do Ser e os efeitos linguísticos de que o Eu (orador) se serve para persuadir o Tu (público/ouvinte) - diversos estudiosos da linguagem dedicaram suas pesquisas, principalmente ao longo dos séculos XIX e XX. É, no entanto, com a publicação do Curso de Linguística Geral de Ferdinand de Saussure (1916) que se delineia uma Semântica Estrutural, isto é, uma teoria que fornece os subsídios necessários para descrever e explicar o sentido construído pelas palavras sem levar em conta, por exemplo, sua etimologia e os aspectos suprassegmentais pertencentes à chamada realidade extralinguística.

Linguistas reconhecidamente discípulos de Saussure, Charles Bally, Emile Benveniste e Oswald Ducrot desenvolveram importantes estudos e pesquisas em linguística, cujo objetivo geral em comum era, em especial, o de aprofundar a noção de enunciação na linguagem. No livro Linguistique générale et linguistique française (1932), Bally criou uma teoria geral da enunciação através da qual dissociou, por exemplo, o sujeito falante (ser empírico do mundo) dos sujeitos comunicante e modal (seres de linguagem). Entretanto, é especialmente nos livros Problemas de Linguística Geral I e II de Benveniste 
(1966/1976) que se encontra uma linguística do discurso - do uso da língua - construída com base no pensamento saussuriano. Atualmente, muitos linguistas atribuem a Benveniste o título de "pai da enunciação", considerando o seu vasto trabalho na área. Enquanto esses dois últimos autores pensaram na semântica no domínio de uma linguística da fala (em termos saussurianos), Ducrot construiu uma semântica de um ponto de vista estritamente sistêmico, isto é, de uma linguística da língua (nos termos saussurianos).

No livro Les mots du discours (1980), Ducrot introduz a noção de polifonia em linguística, com inspiração na enunciação de Bally, e a desenvolve em trabalhos posteriores, explicitando a multiplicidade de vozes - que fazem parte do sentido - no interior do enunciado. Porém, embora também seja autor de uma teoria enunciativa, o slogan de Ducrot em linguística é o da argumentação. Com a colaboração de Jean-Claude Anscombre, em 1983, Ducrot publica L'Argumentation dans la Langue, livro que pode ser considerado marco fundador de sua Teoria da Argumentação na Língua (ANL), também denominada Semântica Argumentativa.

Argumentar, segundo Anscombre e Ducrot (1983), nada tem a ver com a atividade de persuasão, de convencimento ou de defesa de um ponto de vista através de argumentos que conduzem a determinada conclusão, visto que essas relações são autorizadas, em geral, no domínio da argumentação retórica, vinculada ao nome de Aristóteles. Para a ANL, argumentar tem a ver com os encadeamentos ditos normativos (em portanto) e com os encadeamentos transgressivos (em no entanto) que o locutor realiza - em vista de seu alocutário - para construir sentido. Por exemplo, quando um locutor enuncia $O$ restaurante está lotado, a significação da frase subjacente a esse enunciado orienta tanto para continuações normativas do tipo de portanto vamos em outro; portanto a comida deve estar terminando; portanto é de boa qualidade, etc., quanto para continuações transgressivas do tipo de no entanto vamos almoçar nele; no entanto sobrará comida para o dia seguinte; no entanto a comida não é de boa qualidade, etc. Esses encadeamentos entre dois predicados são argumentativos, não só porque se realizam numa relação Eu-Tu, mas porque revelam a própria natureza semântica da língua - sistema de signos.

Por ser uma teoria linguística que desenvolve uma concepção platoniana de linguagem (pela teoria da alteridade apresentada e desenvolvida no diálogo O Sofista) - por intermédio das noções saussurianas de relação e de valor - a ANL não está preocupada com os efeitos retóricos revelados no discurso. Desde 1992, Ducrot desenvolve seus estudos e pesquisas com Marion Carel, linguista que apresentou um aprofundamento e uma radicalização da ANL em sua tese de doutorado, por meio da chamada Teoria dos Blocos Semânticos (TBS). Os estudos mais atuais de Ducrot e Carel buscam explicar a relação entre argumentação e polifonia pela chamada Teoria Argumentativa da Polifonia (TAP).

Este número da revista Letrônica - cujo tema é Enunciação e argumentação em semântica - reúne dez artigos desenvolvidos a partir de diferentes perspectivas teóricas, que, de algum modo, descrevem e/ou explicam fenômenos em torno da construção do sentido no discurso. O número é aberto com o artigo "As argumentações enunciativas" de Marion 
Carel, em que a autora dá um sentido novo à noção de "argumentação" no âmbito da TAP, definindo-a como uma teoria que descreve argumentativamente os fenômenos ditos enunciativos. Ao apresentar a TBS, Carel desenvolve conceitos fundamentais da teoria, a saber: o de encadeamento argumentativo (explícito e implícito), de aspecto argumentativo e de quadrado de transposição. A autora descreve e explica, essencialmente, a construção semântico-argumentativa do poema Noite de substituição, de Marc de Larréguy, pelo emprego de determinadas noções da TAP e mostra como é possível analisar a enunciação e a argumentação em corpus literário.

A construção do sentido no discurso literário também é tema do artigo de Lauro Gomes e Bárbara Luzia Covatti Malcorra, em que, pelos encadeamentos argumentativos normativos e transgressivos evocados do miniconto Os ninguéns de Eduardo Galeano e pela explicitação das Pessoas Enunciativas e da atitude discursiva do locutor, os autores mostram o potencial teórico-metodológico da TAP para análise do sentido produzido pelas palavras no discurso literário. Partem da hipótese de que a TAP permite explicitar o sentido global do discurso de modo mais explicativo do que as fases que a antecedem, visto que a matriz de sentido apresentada por essa fase atual da Semântica Argumentativa dá conta não apenas dos elementos oriundos do sistema linguístico, mas também de aspectos decorrentes do uso que o locutor faz da língua para produzir discurso.

No artigo "Considerações acerca do Prefácio de Ducrot, na obra O Intervalo Semântico, de Vogt", Cristiane Dall'Cortivo Lebler e Samuel Henrique Machado explicitam as bases filosóficas da ANL, que passam pelo diálogo O Sofista de Platão. O artigo busca reconstituir o percurso teórico que Oswald Ducrot apresenta, no Prefácio à obra O Intervalo Semântico, de Carlos Vogt, para finalmente propor uma possível resposta à questão levantada pelo linguista francês acerca da natureza do enunciado, de seu valor argumentativo e sobre a suposta relação que a essência de seu objeto de estudo guarda com a própria natureza discursiva como foi entendida pelos sofistas.

Com o propósito de levar a ANL para o ensino de compreensão leitora, Luciana Idiarte Soares Falkenbach e Tânia Maris de Azevedo apresentam uma possibilidade de transposição didática de alguns conceitos da Semântica Argumentativa - principalmente com o objetivo de fornecer, aos professores do ensino superior, subsídios teóricometodológicos para que os estudantes aperfeiçoem o desenvolvimento de suas habilidades de compreensão leitora dos articuladores mas e embora.

No texto "A igualdade em paradoxo: uma abordagem enunciativa", Luiz Francisco Dias e Thalita Nogueira de Souza abordam a concepção de igualdade que fundamentou a decisão do Supremo Tribunal Federal quanto à validade da adoção de cotas para negros nos processos seletivos de ingresso em instituições de ensino superior no Brasil. Para isso, os autores utilizaram conceitos agregados a uma semântica do acontecimento desenvolvida no Brasil a partir da perspectiva teórica de Oswald Ducrot. 
Por sua vez, Emanuele Mendonça de Freitas, Heloísa Pedroso de Moraes Feltes e Sílvia Maria Zanella desenvolvem, no texto "1984: totalitarismo, vigilância e censura: retomando a questão do determinismo linguístico", uma revisão da tese de Sapir-Whorf quanto ao determinismo linguístico, tomando como parâmetro a dinamicidade do controle social do dizer apresentado na obra mais importante de Orwell, 1984. As autoras se apoiam em Foucault para reafirmar a fragilidade da Hipótese Sapir-Whorf.

A constituição do sentido na leitura é o principal objeto do texto de Samanta Kélly Menoncin Pierozan, intitulado "A instância enunciativa na leitura: a relação 'eu-tu' pela palavra do presidente". Tendo em vista a análise de parte de um manual de integração entre direção e funcionários de uma empresa gaúcha, a autora aborda a relação "eu-tu" na fala do seu presidente, dirigida aos empregados, defendendo a ideia segundo a qual a instância do discurso, considerada do ponto de vista benvenistiano, é afetada por uma relação hierárquica a qual uma abordagem enunciativa permite descrever.

Com base em narrativas produzidas por alunos do 6ํano do ensino fundamental, o artigo "Relações intersubjetivas e marcas modais na produção textual" apresenta as relações subjetivas depreendidas por marcas léxico-gramaticaisenunciativas. As autoras, Marilia Blundi Onofre e Solange Christiane Gonzales Barros, buscam na Teoria das Operações Enunciativas e Predicativas, de autoria de Antoine Culioli, o fundamento teórico para a realização da análise. Com isso, busca-se expor os processos de geração da linguagem na atividade de produção textual, no âmbito das atividades epilinguística, linguística e metalinguística.

No artigo "A constituição de sentido no discurso publicitário sob a perspectiva da Semântica Argumentativa", Leyla Ely e Alessandra Silveira Bez analisam textos publicitários de épocas distintas com base na Teoria dos Blocos Semânticos, desenvolvida por Carel e Ducrot. Especificamente, as autoras observam pares de anúncios de cigarro, bebida alcóolica e automóvel, veiculados na internet, visando articular palavras e imagens, o que permitiu a elas demonstrar o caráter complementar da imagem em relação ao discurso verbal. O ganho teórico do trabalho está na associação da imagem à explicitação de sentido intralinguística de Carel e Ducrot.

Por fim, no texto "Teoria polifônica da enunciação: claro enigma", Andréia Inês Hanel Cerezoli e Carla Roberta Sasset realizam uma abordagem da leitura com base na Semântica Argumentativa, desenvolvida por Oswald Ducrot na França e Barbisan e Azevedo no Brasil. 0 artigo aponta aspectos do desenvolvimento da habilidade de reconstrução de sentidos no discurso, tendo em vista a própria materialidade linguística. $\mathrm{O}$ argumento principal do texto está centrado na ideia segundo a qual uma atividade de leitura que permite equiparar os alunos, independentemente das suas experiências de vida, deve ser centrada na materialidade linguística, através da qual se pode desenvolver a habilidade de reconstituição de sentidos na leitura.

Desejamos uma boa leitura a todos! 